\title{
The evolution of cyanide heap leach closure methods
}

\author{
J.V. Parshley SRK Consulting, USA
}

M.A. Willow SRK Consulting, USA

R.J. Bowell SRK Consulting, UK

\begin{abstract}
The last two decades have seen a significant evolution in the approaches used to close gold heap leach pad facilities in an environmentally responsible manner. With the promulgation of new cyanide regulations in the State of Nevada, USA in 1989, the mining industry was faced with the need to develop new methods to safely close cyanide heap leach pads in a manner that eliminated long-term risks associated with cyanide and other chemical constituents that could be discharged from the heap leach pads following closure.

Initially, rinsing of the heaps was thought to be the only approach to reduce concentrations of cyanide, and this was reflected in the new regulations as a requirement to rinse heaps, unless other methods could be demonstrated to adequately stabilise the spent ore and solutions. However, the regulations were unclear as to when closure of the heap began and if circulation of process solutions, after cyanide addition ceased, constituted rinsing.

Many closure plans developed during the early years immediately following promulgation of the new regulations assumed that rinsing would be done with fresh water in quantities of up to three times the total pore volume of the heap based solely on the results of a study published in 1996 (Cellan et al.). If implemented, this would result in the consumption of significant quantities of clean water in a region where water resources are limited, and the benefits of freshwater rinsing were not always apparent. Rinsing heaps during closure also generated large quantities of additional "process" solutions that required management through other methods, such as forced evaporation, or chemical or biological treatment.

By the late 1990s, the mining industry had closed enough heap leach pads to allow review of ideas and to use this to make changes in the regulations and approaches employed by the industry. A better definition of when heap closure begins was needed. The currently accepted criterion for closure was after economic gold recovery ceases. Continued research on this led to the demonstration for closed heaps that additional rinsing after the residual gold recovery period is often not needed to reduce cyanide risks from the heap drainage because the more toxic forms of cyanide volatilise and other deleterious elements become mobile as solutions are recirculated through the heap (Bowell et al., 2009).

To address the shortcomings of heap rinsing as the primary method of chemical stabilisation of spent ore, a number of approaches were tried, and many of the early approaches were abandoned in favour of more practical and economic methods which were equally effective. This paper documents the history of heap leach closure approaches since the late 1980s and discusses the evolution of understanding and consequently the methods proposed to stabilise spent heap ore during closure. Data from several closed heaps are presented as illustrations of the progression of approaches to heap rinsing. Current trends in the existing best practice and their probable impact on the focus of future of heap closure methods are also discussed.
\end{abstract}

\section{Introduction}

In the two decades since the first modern gold heap leach facilities were closed, the approach to closure of heap leach pads has evolved considerably. In particular, rinsing of leach pads, initially considered an integral part of heap closure, has since become recognised as generally unnecessary, and often a waste of valuable water resources (Bowell et al., 2009). 
When the first modern heap leach closure regulations were promulgated in the State of Nevada, USA, in 1989, the requirements for closure of heap leach facilities were based on limited information and a number of presumptions and suppositions. Based on these regulations, some mine operators and regulators in the early 1990s came to believe that 'rinsing' was essential in order to remove cyanide, and they were expected to continue rinsing after gold recovery ceased, and include the operational costs for this longterm rinsing in their financial assurance calculations.

As the closures of more heap leach facilities were implemented by the late 1990s, a number of the regulatory requirements and accepted approaches were tested under field conditions and were found to be unnecessary or impractical and in some cases, such as rinsing could exasperate or cause water quality degradation. Fundamentally, the role of rinsing was questioned as a necessity to chemically stabilise the spent heap leach ore. This paper provides an overview of the change in industry practice and the justification for these changes based on field experience.

\section{Early closure regulations}

Many early heap leach pads were designed such that spent ore would be pushed off the liner system in order to achieve the desired post-closure landform (Comba and McGill, 1991; McNeamy, 1996). Because spent ore had been in contact with process solutions containing cyanide during operations, the new regulations required that the spent ore be chemically stabilised before it was removed from the liner system. Conventional thinking at the time was that this would require rinsing, and the regulations reflected this. The 1989 Nevada regulations (NAC 445A) required that "spent ore which has been left on pads or which will be removed from a pad must first be rinsed until:

- WAD cyanide levels in the effluent rinse water are less than $0.2 \mathrm{mg} / \mathrm{l}$.

- The $\mathrm{pH}$ level of the effluent rinse water is between 6.0 and 9.0.

- Contaminants in any effluent from the processed ore which would result from meteoric waters would not degrade waters of the state." (NDEP, 2012)

If stabilisation could not be achieved using rinsing, the operator had the option of demonstrating that the spent ore did not pose a risk to surface or ground water by alternative methods.

Although the regulations did not specify the rinse media, some operators and regulators at the time assumed that fresh water was to be used, although no studies had been completed to support this conclusion. This assumption may have come from standard practices used to decontaminate chemical containers in many jurisdictions via rinsing with fresh water (USEPA, 2005). Regardless, many closure plans and cost estimates of the time were based on this assumption.

The quantity of rinsing required was also the subject of debate at the time. Early studies indicated that three pore volumes of water could reduce Weak Acid Dissociable (WAD) cyanide levels to the regulatory standard of $0.2 \mathrm{mg} / \mathrm{L}$ (Cellan et al., 1996). This one example from the Santa Fe heap leach pad in Nevada was used to support the concept of rinsing to reduce cyanide, but was also considered an indication of the volume of water required. The standard chemical container rinsing procedure, which also included triple rinsing with water, may have also influenced this assertion.

Many closure plans of the time incorrectly assumed that the 'pore volume' described in Cellan et al. (1996), was the volume of void space within a heap or the volume of fluid required to saturate the spent ore, which is actually the definition of a 'bed volume' (Bowell et al., 2009). In fact, the definition of 'pore volume' used in Cellan was the metallurgical definition, which defines void space within the particles of a solid mass, but not the void space between the particles (Figure 1).

This misunderstanding of pore volume lead to significant overestimates of the quantity of rinse solution required for heap closure in many closure plans. In fact, the most common definition of a pore volume used to describe the process of heap stabilisation by rinsing is the amount of water required to fill all the pore space within and between all of the particles in a heap minus the quantity of water that will remain in the 
heap due to matric suction after it is allowed to freely drain (field capacity). Recent work by Zhan et al. (2012) indicates that less than 1.5 pore volumes would be required to reduce WAD cyanide concentrations below $0.2 \mathrm{mg} / \mathrm{L}$, assuming reduction by dilution alone.

Table 1 Leach pad height simulation column neutralisation rinse data summary, Santa Fe Mine leach pad ore (modified after Cellan et al., 1996)

\begin{tabular}{ccccccccc}
\hline \multicolumn{2}{c}{ Cum. Site Barren Solution Applied } & \multicolumn{5}{c}{ Effluent Analysis } \\
& $\begin{array}{c}\text { tons/ton } \\
\text { Day }\end{array}$ & Pore & \multicolumn{5}{c}{ mg/L } \\
\hline 0 & 0.087 & 0.369 & & & & & \\
$1-9$ & 0.163 & 0.694 & 9.9 & 207 & 0.18 & 1.03 & 110 \\
19 & 0.239 & 1.017 & 8.6 & 2 & 1.2 & 8 & 17.4 \\
26 & 0.292 & 1.244 & 8.6 & 80 & 0.55 & 4.04 & 163.5 \\
30 & 0.315 & 1.342 & 8.3 & 58 & 0.35 & 2.04 & 100.8 \\
40 & 0.391 & 1.666 & 8.2 & 8.2 & 0.12 & 0.54 & 6.3 \\
50 & 0.467 & 1.99 & 8.3 & 11 & 0.12 & 0.55 & 19.7 \\
60 & 0.543 & 2.314 & 8.1 & 3.1 & 0.03 & 0.15 & 1.9 \\
70 & 0.619 & 2.638 & 8.2 & 0.3 & 0.0 & 0.0 & 0.2 \\
80 & 0.695 & 2.963 & 8.2 & 0.2 & 0.0 & 0.0 & 0.0 \\
94 & 0.809 & 3.449 & 8.1 & 0.1 & 0.0 & 0.0 & 0.0 \\
118 & 0.791 & 3.373 & 7.5 & 0.1 & 0.0 & 0.0 & 0.0 \\
\hline
\end{tabular}

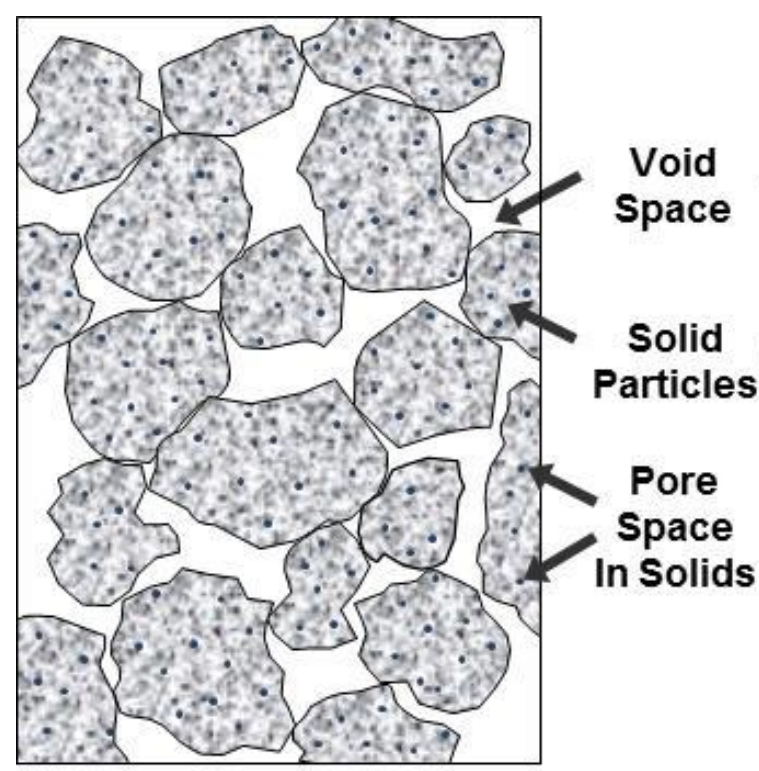

Metallurgical Pore Volume

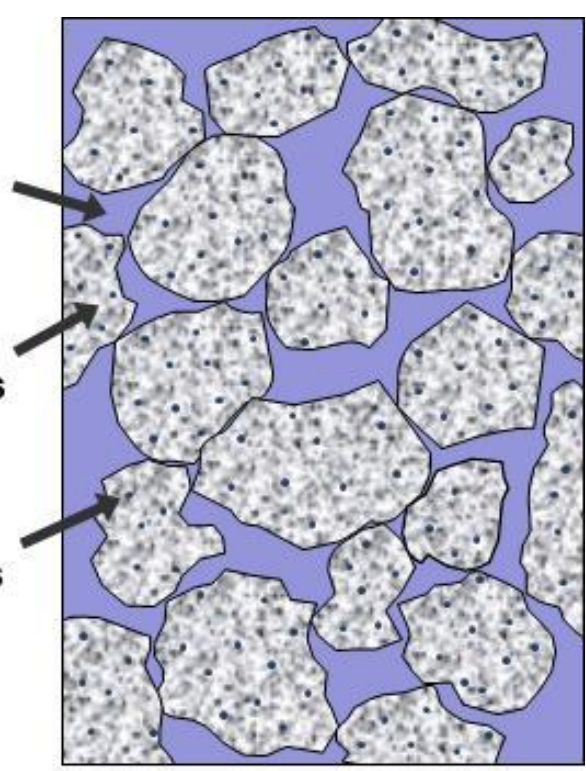

Pore (Bed) Volume

Figure 1 Pore volume versus bed volume 


\section{$3 \quad$ Heap solution chemistry}

The purpose of heap rinsing requirements in the regulations was to reduce chemical constituents in the heap drainage, particularly cyanide, in an attempt to minimise not only potential long-term impacts to groundwater resources, but also reduce the toxicity of the solutions to terrestrial and avian wildlife that could be exposed to draindown waters post closure when more passive management scenarios of the waters were enacted. However, it quickly became apparent to the industry that heap rinsing as a closure activity was generally not required to reduce cyanide concentrations to regulatory standards, nor was it always beneficial in reducing levels of metals, metalloids and other constituents.

The more toxic forms of cyanide (free and WAD) are associated with the liquid phase in a heap leach pad, and have been demonstrated to rapidly decay by volatilisation of hydrogen cyanide (HCN) gas, particularly near the surface of pad (Logsdon et al., 1999). During operations, the $\mathrm{pH}$ in heap leach pads is artificially maintained above $\mathrm{pH} 9.5$ in order to minimise the volatilisation of $\mathrm{HCN}$ from free cyanide and weaker metal-cyanide complexes (Mudder and Smith, 1992).

At closure, drip irrigation systems on the heap leach pad are often replaced with nozzles which spray solutions into the air. This not only reduces the volume of water through evaporation, but causes the reabsorption of $\mathrm{CO}_{2}$ gas from the atmosphere, which produces carbonic acid, and lowers the $\mathrm{pH}$ of the solutions. This $\mathrm{pH}$ reduction causes the WAD cyanide complexes, particularly copper, to begin to breakdown through chemical dissociation. The free cyanide formed by this process volatilises from the solution into the air as HCN (ATSDR, 2000).

Stronger metal-cyanide chelates, such as ferrocyanides, often associated with the solids on a heap leach pad, will decay more slowly. Cobalt and iron cyanide chelates decay through photolytic breakdown in the presence of ultraviolet light such as sunlight. The rate at which these complexes decay depends on the initial concentration, the $\mathrm{pH}$ of the solutions, and the intensity of ultraviolet light (ATSDR, 2000).

Although the stronger metal-cyanide complexes decay more slowly, their non-toxic nature reduces the risks associated with their presence in the heap solids following closure. Ferrocyanides in particular are nontoxic because of their chemical stability (Mudder et al., 2001) and are often used as food additives and anticaking agents in table salt (Schulz and Hadeler, 2003).

Other constituents are likely to remain in heap drainage solutions after concentrations of cyanide compounds have decreased, and may even increase through rinsing because the $\mathrm{pH}$-redox state of heap solutions will ultimately determine the chemistry of drainage from a heap, and long-term rinsing of spent heap ore is likely to alter the $\mathrm{pH}$-redox conditions in the heap (Bowell et al., 2009). This can result in the release of constituents though desorption and dissolution of previously stable constituents (Figure 2).

Concentrations of a number of constituents, including arsenic, antimony, thallium, boron, barium, cadmium, calcium, chloride, chromium, cobalt, fluoride, manganese, molybdenum, nitrate, potassium, sodium, strontium, sulfate, total dissolved solids and vanadium, have been demonstrated to remain in solution and even increase, long after the permit limits for cyanide have been reached in a number of heap leach pads (Parshley and Bowell, 2001). These constituents can pose toxicological threats to ecological receptors that may be exposed to heap drainage allowed to surface express as part of long-term solution management activities.

As an example, a column rinsing test conducted on Gold Acres heap material revealed the presence of leachable metals and metalloids as soluble salts stored in the material (Bowell et al., 2009). Results of the field rinsing test indicated rinsing the Gold Acres Heap with recirculated barren solution does not have any benefit in decreasing the solute load of the heap. In particular, arsenic, cadmium, chloride, nitrate and total dissolved solids concentrations did not decrease in response to multiple rinse cycles (Bowell et al., 2009). An increase in some constituents during the final freshwater recirculation rinses of the column test indicated that multiple freshwater rinse cycles will change the $\mathrm{pH}$-redox conditions of the heap and adsorbed constituents that were previously stable may become remobilised (Bowell et al., 2009). 


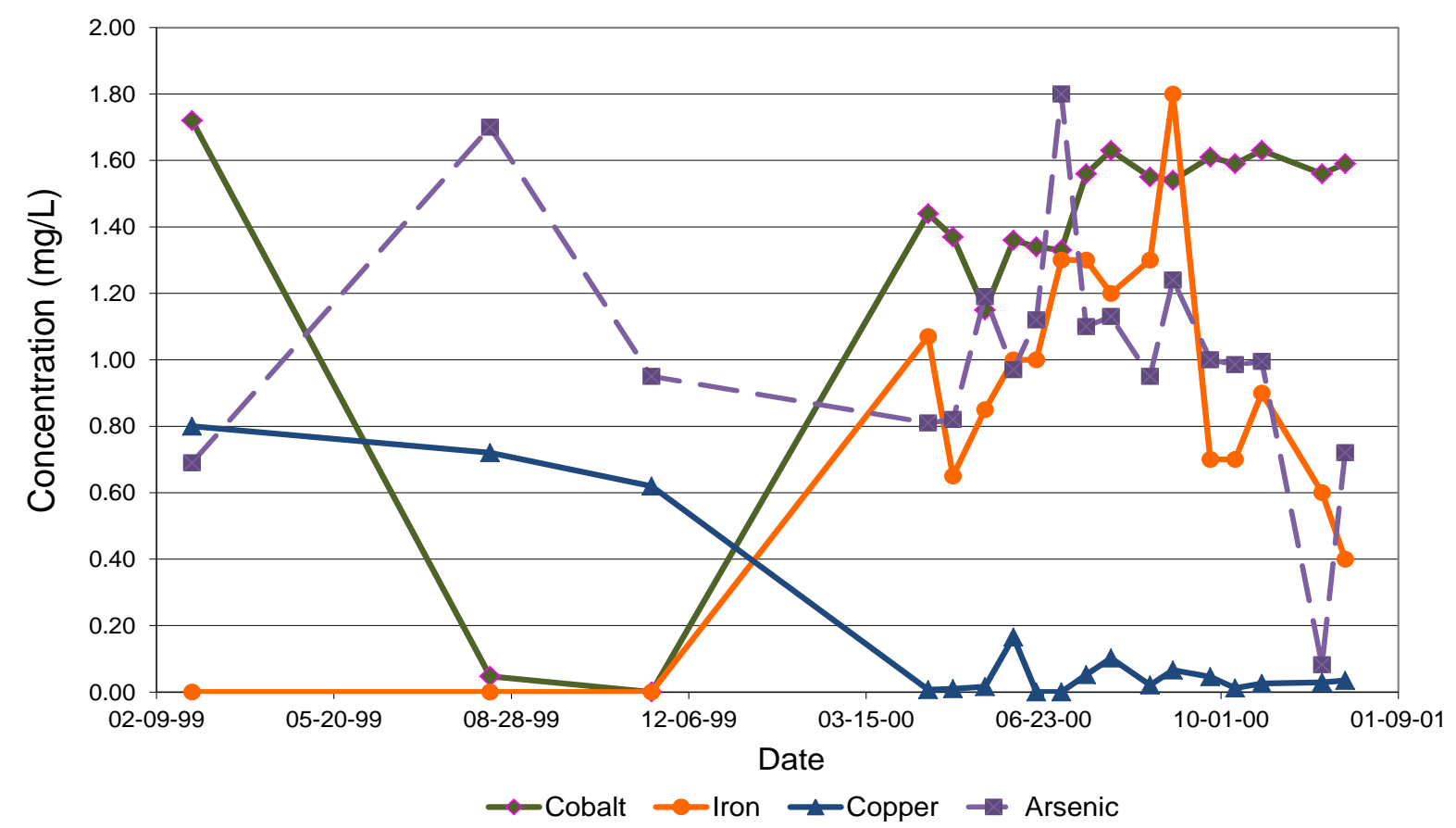

\section{Figure 2 Release of heap metals during rinsing (after Bowell et al., 2009)}

A comparison between the column test results and the monitoring data collected during field scale rinsing at Gold Acres confirmed that rinsing spent ore with re-circulated barren solution is not effective in decreasing solute loadings. Additionally, the column test indicated that applying multiple freshwater rinses to the heap exacerbated the release of constituents by changing the $\mathrm{pH}$-redox conditions of the heap. Consequently, rinsing of the Gold Acres heap facilities was not considered a viable method for heap closure and long-term chemical stabilisation of the spent oxide ore. Furthermore, the Gold Acres Heap case study indicated rinsing heap material with recirculation barren solution will produce no significant change (i.e. improvement) in the heap solution chemistry. In addition, rinsing with freshwater will result in a higher risk for potential degradation than not rinsing at all.

\section{$4 \quad$ Recirculation versus rinsing}

Recirculation is the process of recycling process solutions to extract residual gold even after cyanide addition has ceased. Rinsing is the term used to describe the application of water (without cyanide addition) to spent heap ore for the purposes of removing deleterious constituents. However, in the context of closure many people expand the term rinsing to include the recirculation, which can lead to confusion regarding the actual closure activities required to close a heap.

In order to clearly delineate between operations and closure during heap closure planning, it is important to define when operations end and when the closure process begins. The most common definition of the beginning of heap closure is the time when economic gold recovery ceases. This usually occurs at some point in time after cyanide addition has been halted. Typically, economic gold recovery will continue for months after the operator ceases cyanide addition. This period is often referred to as residual gold recovery. When the residual gold recovery period ends, closure begins.

Using this definition of heap closure, there are two reasons that operators continue to re-circulate heap solutions during closure: solution management and removal of deleterious constituents. The first is a common practice. The second is often not necessary or not practical to reduce most constituents if sufficient recirculation has occurred during the residual gold recover period.

Recirculation for solution management is intended to reduce the solution inventory in the heap system to a level that allows passive management of residual draindown and infiltrating water without discharge from 
the site. This period of active solution management is part of closure and often includes the use of methods and equipment designed to rapidly evaporate excess solutions. This could include replacing the standard emitters with 'misters' designed to reduce the water droplet size or mechanical evaporators (designed based on snow making equipment used by the ski industry). In some instances, enhanced biological treatment methods were shown to be effective at accelerating cyanide degradation, but natural degradation generally occurred at acceptable rates to achieve closure without treatment.

Rinsing with process solutions or water for the removal of deleterious constituents is not generally needed and often can have the opposite result - releasing constituents that are fairly stable in the heap as described above (Bowell et al., 2009). Much of the cyanide reduction in a heap actually occurs during recirculation for residual gold recovery, and rest periods without circulation of solutions, which can result in reduction of WAD cyanide levels by as much as $99 \%$ (Figure 3 ). When economic recovery of gold ceases and closure begins, continued rinsing to reduce cyanide concentrations is often not required.

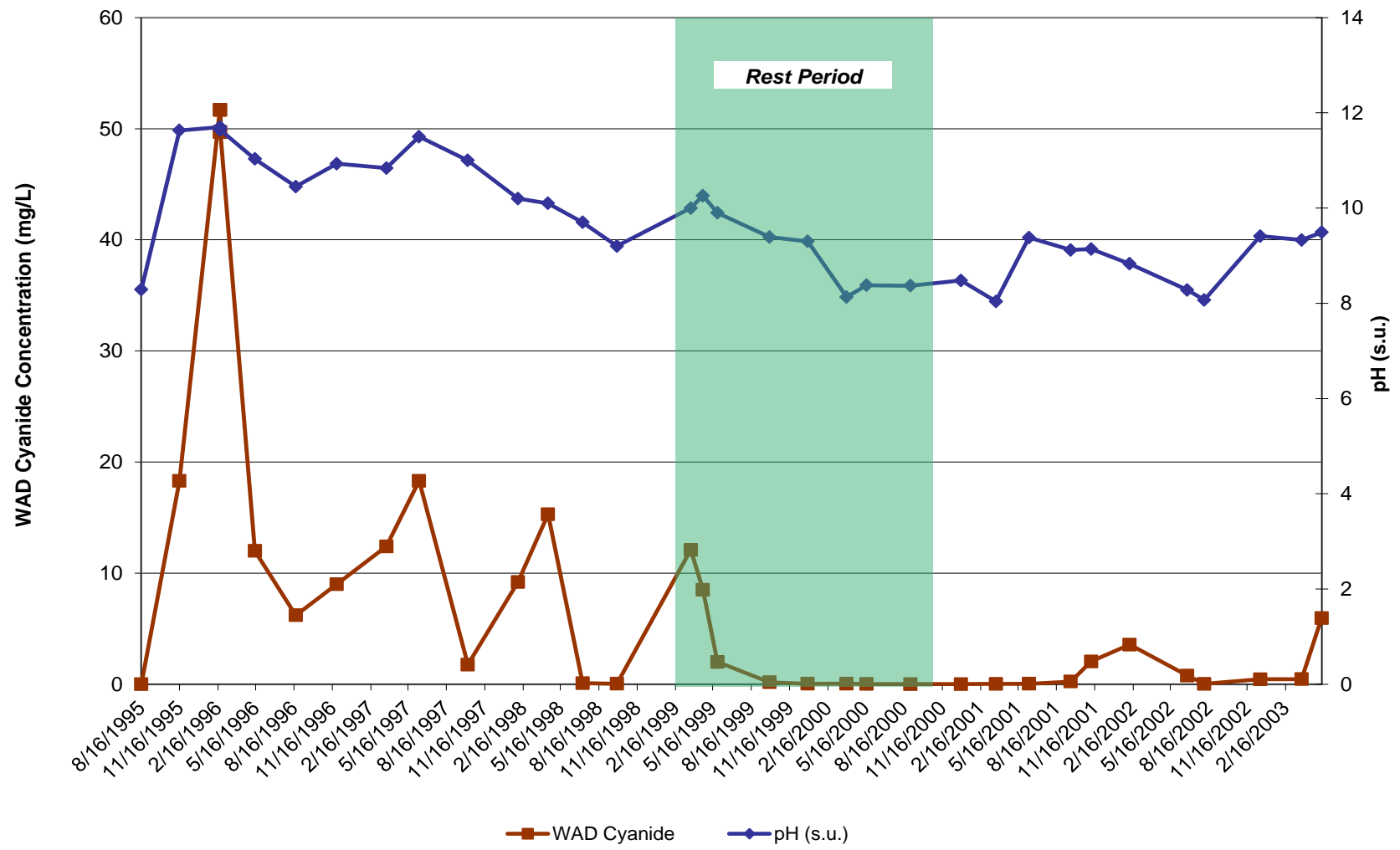

Figure 3 Cyanide reduction during rest cycle (Bowell et al., 2009)

Further, multiple rinsing or recirculation of heap solutions does not guarantee improved water quality as indicated by Miller et al. (1999) but rather has the potential to reduce long-term water quality due to changes in the $\mathrm{pH}$-redox environment of the heap. It is postulated that rinsing after reduction of WAD cyanide from the heap material only disperses other constituents rather than removing them. Geological abundance in the heap ore coupled with the low release rates of many constituents will result in long-term leaching by rinsing.

\section{$5 \quad$ New thinking}

By the late 1990s, enough heap leach pads had been closed and sufficient empirical data collected to justify revision of heap closure approaches commonplace at the beginning of the decade. Through experience with actual heap closures, the gold mining industry broadened both knowledge and expertise in sound closure planning and implementation. New thinking was required for heap closure, and it included:

1. A better definition of when closure begins was needed. 
2. Additional rinsing after the residual gold recovery period is not generally needed to reduce cyanide levels in the heap drainage.

3. Prolonged rinsing could cause a release of previously stable constituents from the spent heap ore.

4. Regulations based on the presumption that rinsing was required to stabilise spent heap ore were inconsistent with the best available information from actual heap closures.

By the end of the 1990s, most closure plans defined the beginning of heap closure as the time when economic gold recovery ceases. By defining closure in this manner, rinsing primarily became a method to reduce solution inventory and manage water with the goal of shortening the active solution management period.

Although closure requirements have been shown to vary greatly between sites, rinsing specifically to reduce cyanide concentrations in heap solutions is generally recognised as unnecessary, and freshwater rinsing is almost never included as part of modern heap closure plans. Use of fresh water for rinsing is expensive due to the cost of obtaining the water, as well as the cost managing the additional inventory created by a fresh water rinse. In arid or semi-arid environments, where water resources are scarce, use of fresh water for heap rinsing is also recognised as a waste of a valuable resource.

Mine bankruptcies in 2000 and 2001 also led to changes in the financial assurance requirements in many jurisdictions (Parshley et al., 2009). Because financial assurance calculations now included detailed estimates of fluid management costs, designing heap closures to reduce long-term drainage management became a priority as methods to limit long-term fluid management costs.

By 2005, the new focus for heap closure design shifted to methods for inventory reduction and optimisation of closure covers intended to minimise the risks associated with long-term infiltration and seepage from the leach pads. New technologies for passive management of water, including the use of evaporation and evapo-transpiration cells along with biological treatment were applied.

In 2007, the Nevada regulations were revised to reflect the previous 15 years of industry experience with heap closure. References to rinsing were removed from the regulations and a performance based standard focusing on demonstrating protection of groundwater resources became the new requirement for chemical stabilisation of spent heap leach ore.

\section{Conclusions}

By the mid-1990s, the mining industry had gained enough experience to realise that rinsing of heaps beyond what was needed to extract residual gold and reduce fluid inventories was unnecessary and wasteful. A number of heap leach closures had demonstrated that prolonged rinsing was not generally required to reduce cyanide concentrations to regulatory standards and some closure data indicated that recirculation and rinsing could actually increase a number of other constituents in heap drainage and cause greater degradation of groundwater.

This experience led to changes in regulations and changes to proposed closure approaches at many mine sites. Focus shifted to inventory reduction methods and covers designed to reduce infiltration of meteoric water into the heap and passive technologies for the long-term management of heap drainage solutions.

\section{References}

ATSDR (2000) Agency for Toxic Substances and Disease Registry. US Center for Disease Control, Petitioned Public Health Assessment, Cripple Creek and Victor Gold Mining, Cripple Creek, Teller County, Colorado.

Bowell, R.J., Parshley, J.V., McClelland, G., Upton, B. and Zhan, G. (2009) Geochemical evaluation of heap rinsing of the Gold Acres Heap, Cortez Joint Venture, Nevada, Minerals Engineering, Vol. 22, Issue 5, pp. 477-489.

Cellan, R.R., Cox, A.D., Barnes, R. and McClelland, G.E. (1996) Comparison of laboratory and commercial neutralization - rinse data for gold heap leach operation, Presented at the Annual Meeting and Exhibit Society for Mining, Metallurgy, and Exploration Inc., Phoenix, Arizona, March 11-14, 1996, http://www.homestake.com/health_safety/health_safety_sublevels/reports /other_reports/envcell.htm 
Comba, P.G. and McGill, S.L. (1991) Rinsing of spent precious metal ores for heap leach decommissioning, in Proceedings Symposium of Environmental Management of the 1990's, Society of Mining Engineering, Published by the Society of Mining Engineering, Littleton, Colorado.

Logsdon, M., Hagelstein, K. and Mudder, T. (1999) The management of cyanide in gold extraction, International Council on Metals and the Environment.

McNeamy, R.L. (1996) Decommissioning of a selected heap leach dump, International Journal of Surface Mining, Reclamation and Environment, Vol. 10, Issue 4.

Miller, G.C., Hoonhout, C., Watkins Miller, W. and Miller, M.M. (1999) Geochemistry of closed heaps: A rationale for drainage water quality, D. Kosich and G. Miller (eds), Closure Remediation and Management of Precious Metal Heap Leach Facilities, Reno, Nevada, 14-15 Januray 1999, pp. 37-45.

Mudder, T. and Smith, A. (1992) Solution management during decommissioning of heap leach operations, in Proceedings 121st Annual SME Meeting and Exhibit, The Society of Mining, Metallurgy and Exploration Inc.

Mudder, T., Botz, M. and Smith, A. (2001) Chemistry and treatment of cyanidation wastes, 2nd ed.

NDEP (2012) Nevada Division of Environmental Protection. 1989 Nevada Administrative Code regulations (NAC) 445A, Water Controls, State of Nevada, Bureau of Mining Regulation and Reclamation, viewed 02/07/2012, http://ndep.nv.gov/bmrr/regs.htm.

Parshley, J.V. and Bowell, R.J. (2001) Environmental geochemistry of heap leach closure, Abstract Volume, 20th IGES, Santiago, Chile, pp. 92-96.

Parshley, J.V., Baumann, W. and Blaxland, D. (2009) An evolution of the methods for and purposes of mine closure cost estimating, in Proceedings Fourth International Conference on Mine Closure (Mine Closure 2009), A.B. Fourie and M. Tibbett (eds), 9-11 September 2009, Perth, Australia, Australian Centre for Geomechanics, Perth, pp. 187-200.

Schulz, H. and Hadeler, A. (2003) Deutsche Forschungsgemeinschaft, Geochemical processes in soil and groundwater: measurement-modelling-upscaling, Wiley-VCH, p. 67.

USEPA (2005) US Environmental Protection Agency. Introduction to Containers (40 CFR Parts 264/265, Subpart I; §261.7), USEPA Publication on Solid Waste and Emergency Response (5305W) EPA530-K-05-010.

Zhan, G., Haggarty, S. and Ludwick, W. (2012) Hydrological evaluation of gold leach pad rinsing, Mine Water and the Environment, doi:10.1007/s10230-012-0193-5, pp. 1-5. 